\title{
A RESEARCH ON THE EFFECT OF CUTTING PARAMETERS ON CUTTING FORCE IN FLAT GRINDING USING SEGMENTED GRINDING WHEEL
}

\author{
Nguyen Thi Phuong ${ }^{1, *}$, Nguyen Thi Phuong Giang ${ }^{2}$, Nguyen Tien Dong ${ }^{3}$ \\ ${ }^{1}$ General Department of Logistics - Ministry of Public Security, No 80 Tran Quoc Hoan Str., \\ Cau Giay dist, Ha Noi \\ ${ }^{2,3}$ School of Mechanical Engineering, Hanoi University of science and Technology, \\ No 1 Dai Co Viet Str., Hai Ba Trung Dist., Ha Noi \\ "Email:phuongphucbao@gmail.com
}

Received: 5 December 2016; Accepted for publication: 25 August 2017

\begin{abstract}
This article represents the result of a research on the impact of cutting parameters including the number of segments, cutting depth and feed rate on cutting force $\mathrm{P}$ in grinding hardened steel SKD11 using segmented grinding wheel by Taguchi method and analysis of variance (ANOVA). The result released the information of the relationship between the number of segments, cutting depth and feed rate and its interactions with cutting force. Local optimal value of cutting force can also be determined with minimal cutting force and low surface roughness when machining the SKD11 harden steel using segmented grinding wheel.
\end{abstract}

Keywords: cutting force, Taguchi method, ANOVA, cutting depth, surface grinding.

\section{INTRODUTION}

Grinding force caused the elastic deformation of the technology system, vibration and thermal in cutting areas. It is also used to determine the mode of grinding wheel wear. When shear stress increases, the grinding wheel's life reduces, reduced machining accuracy and surface roughness increases. In particular, the immediate change of the shear is the main reason causing the vibration of the wheel and other types of errors [1,2]. Julie Z. Zhang [3] and Taranveer Singh [4] and colleagues used the Taguchi method to find the optimal process parameters. Some authors in Vietnam, [5] and [6], studied the influence of some process parameters, but using traditional methods, therefore it was a large number of experiments too. There is no research of the influence of cutting parameters to cutting force in machining SKD11 harden steel using segmented grinding wheel. This paper presents the results of studying the effects of grinding wheel segmented, depth of cut and feed rate to cutting force by Taguchi methods and the analysis of variance (ANOVA) in order to minimize cutting forces.

\section{OBJECT AND RESEARCH METHODOLOGY}

\subsection{Taguchi method [7]}


Taguchi method is to determine the influence of some process parameters to the mean and variance of the process performance characteristics and to figure out how well this process works using the orthogonal matrix.

There are 3 input parameters with 3 levels, L9 matrix with 4 columns for 4 parameters (P1 P4). Therefore, the right column can be ignored. From that L9 orthogonal matrix is used to form 3 parameters and 3 levels as shown in Table 1 .

The affecting level of cutting force is $\mathrm{I}=3$; the affecting parameters of cutting force is $\mathrm{J}=$ 3 ; the number of trials is $\mathrm{K}=3$; and the number of interation is $\mathrm{L}=3$.

Table 1. Orthogonal matrix according Taguchi L9 of 3 parameters and 3 levels.

\begin{tabular}{|c|c|c|c|c|}
\hline Experiment & $\mathbf{P}_{\mathbf{1}}$ & $\mathbf{P}_{\mathbf{2}}$ & $\mathbf{P}_{\mathbf{3}}$ & $\mathbf{P}_{\mathbf{4}}$ \\
\hline 1 & 1 & 1 & 1 & 1 \\
\hline 2 & 1 & 2 & 2 & 2 \\
\hline 3 & 1 & 3 & 3 & 3 \\
\hline 4 & 2 & 1 & 2 & \\
\hline 5 & 2 & 2 & 3 & \\
\hline 6 & 2 & 3 & 1 & 2 \\
\hline 7 & 3 & 1 & 3 & 1 \\
\hline 8 & 3 & 2 & 1 & 2 \\
\hline
\end{tabular}

where: P1 is feed rate, P2 - cutting depth, P3 - the number of segment;1, 2 and 3 - the low, medium and high level of machine parameters, respectively.

In order to minimal cutting force we need to calculate the signal to noise ratio $\eta \mathrm{S} / \mathrm{N}$

$$
\eta_{i}=S / N_{i}=-10 \log \left(\frac{1}{n} \sum_{i=1}^{u} y_{i}^{2}\right)
$$

where: $\mathrm{n}$ is the number of interation; and $\mathrm{y}_{\mathrm{i}}$ is cutting force value by each experiment.

\subsection{Analysis of variance ANOVA [7]}

Table 2. Parameters of Analysis of Variation.

\begin{tabular}{|l|c|c|c|c|}
\hline \multicolumn{1}{|c|}{ Variation } & F & Sum of squares & Mean squares & C\% \\
\hline Between Colums (C) & $\mathrm{J}-1$ & $\mathrm{SS}_{\mathrm{c}}$ & $\mathrm{MS}_{\mathrm{C}}$ & \\
\hline Between Rows (R) & $\mathrm{K}-1$ & $\mathrm{SS}_{\mathrm{R}}$ & $\mathrm{MS}_{\mathrm{R}}$ & \\
\hline Between Layers (L) & $\mathrm{L}-1$ & $\mathrm{SS}_{\mathrm{L}}$ & $\mathrm{MS}_{\mathrm{L}}$ & \\
\hline Interaction C $\times \mathrm{R}$ & $(\mathrm{J}-1)(\mathrm{I}-1)$ & $\mathrm{SS}_{\mathrm{CR}}$ & $\mathrm{MS}_{\mathrm{CR}}$ & \\
\hline Interaction C $\times \mathrm{L}$ & $(\mathrm{J}-1)(\mathrm{K}-1)$ & $\mathrm{SS}_{\mathrm{CL}}$ & $\mathrm{MS} \mathrm{CL}_{\mathrm{C}}$ & \\
\hline Interaction R $\times \mathrm{L}$ & $(\mathrm{I}-1)(\mathrm{K}-1)$ & $\mathrm{SS}_{\mathrm{RL}}$ & $\mathrm{MS} \mathrm{SL}_{\mathrm{RL}}$ & \\
\hline $\begin{array}{l}\text { Interaction } \\
\mathrm{C} \times \mathrm{R} \times \mathrm{L}\end{array}$ & $(\mathrm{J}-1)(\mathrm{I}-1)(\mathrm{k}-1)$ & $\mathrm{SS}_{\mathrm{CRL}}$ & $\mathrm{MS} \mathrm{CRL}_{\mathrm{L}}$ & \\
\hline Sum of squares & $\mathrm{N}-1$ & $\mathrm{SS}_{\mathrm{T}}$ & & \\
\hline
\end{tabular}


Analysis of Variance is a statistical technique used to compare the average value of three or more groups. The variance of a two-component observed is variance between groups and groupitself variance.

To analyze the variance we should define some parameters as in Table 2.

\section{EXPERIMENTAL SET UP AND RESULTS}

\subsection{Research Problem}

The concerned problem was to minimize cutting forces by Taguchi method with cutting parameters: number of segment slot $\mathrm{Z}$, feed rate $\mathrm{s}$ and depth of cut $\mathrm{t}$ when machining SKD11 steel using flat surface grinding machine KENT. Experimental data were calculated following ANOVA.

\subsection{Selecting the value of technological parameters}

\subsubsection{Experimental conditions}

The used grinding machine was KENT flat grinding machine, made in TAIWAN. The wheel rotation was $1450 \mathrm{rpm}$.

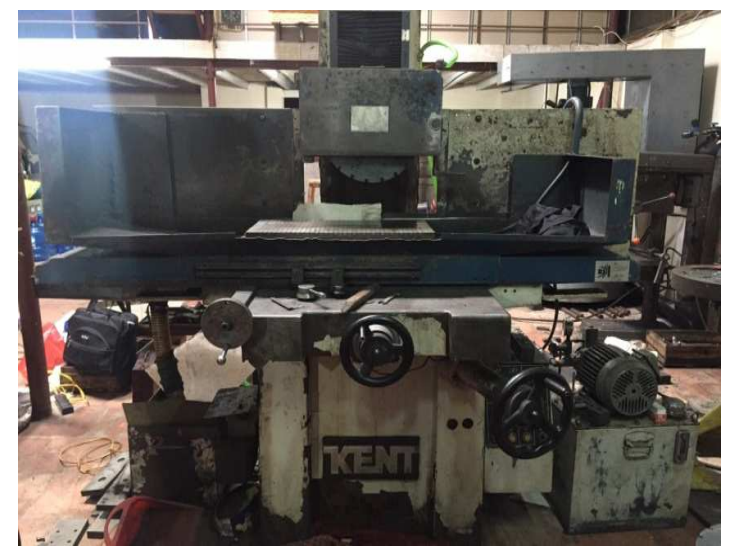

Figure 1. KENT flat grinding machine.

Table 3. Specifications of the KENT flat grinding machine.

\begin{tabular}{|l|c|c|c|}
\hline \multicolumn{1}{|c|}{ Parameter } & Length $\mathbf{( m m )}$ & Width $(\mathbf{m m})$ & Height $(\mathbf{m m})$ \\
\hline 1. Machine dimension & 4,280 & 1,850 & 2,900 \\
\hline 2. Pallet dimension & 700 & 300 & 400 \\
\hline 3. Journey of desk work & 850 & 450 & \\
\hline \multicolumn{4}{|l}{ 4. Capacity of main spindle motor: $4.5 \mathrm{~kW}$} \\
\hline
\end{tabular}

Grinding wheel: In this experiment three grinding wheels were used: 1 conventional and 2 inclined segmented grinding wheels with different the number of segmented. Properties of 
grinding wheels are shown in Table 4. All of wheels were made by Hai Duong grinding wheel company.

Table 4. General parameter of grinding wheel.

\begin{tabular}{|l|c|c|c|}
\hline \multicolumn{3}{|l|}{ Segmented slot's width w: $10(\mathrm{~mm})$} \\
\hline Segmented slot's depth b: & $15(\mathrm{~mm})$ & \\
\hline Segmented slot's angle $\beta$ : & $15\left({ }^{0} \mathrm{C}\right)$ & \multicolumn{3}{l|}{} \\
\hline Grinding wheel & $\begin{array}{c}\text { Number of tracks } \\
\mathrm{Z}\end{array}$ & $\begin{array}{c}\text { Angle between two slotted } \\
\text { continually } \alpha\left({ }^{0} \mathrm{C}\right)\end{array}$ & $\begin{array}{c}\text { Segment rate } \\
\eta(\%)\end{array}$ \\
\hline Grinding wheel 1 & 20 & 18 & 18.19 \\
\hline Grinding wheel 2 & 24 & 15 & 21.83 \\
\hline Grinding wheel 3 & 0 & 0 & 0 \\
\hline
\end{tabular}
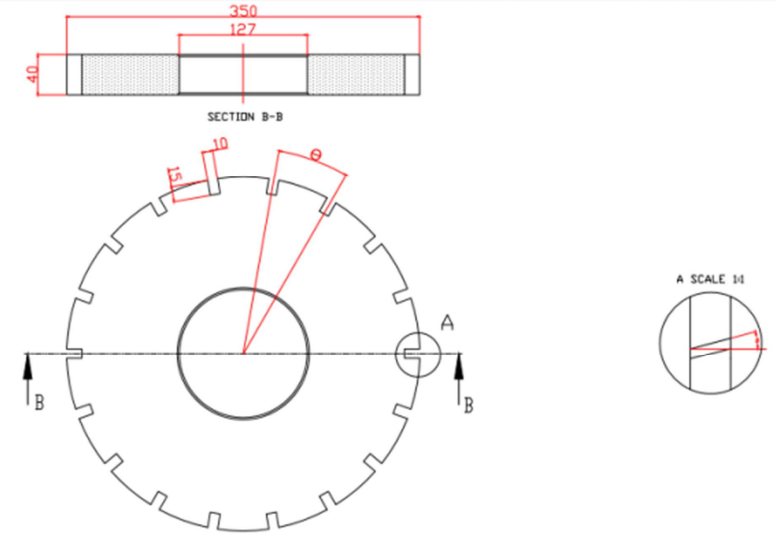

Figure 2. Geometry parameters of segmented grinding wheel.

The measurement was performed using Futek with 3 axis load cell. The accuracy was , A/D converter and DasyLab software for signal processing were used to obtain the data.

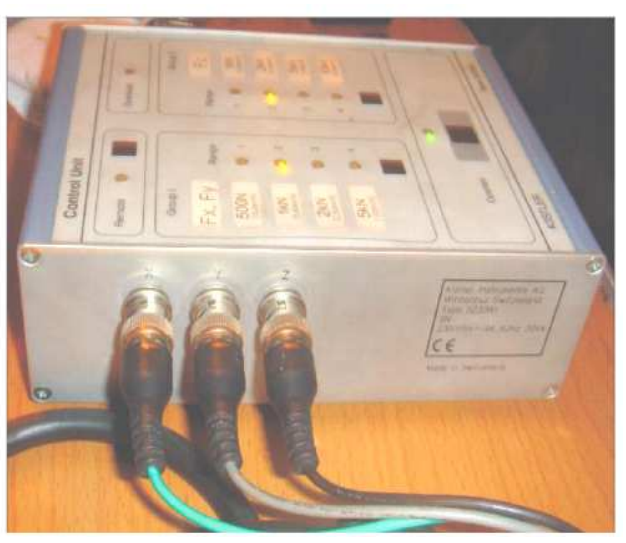

Figure 3a. Card A / D data acquisition.

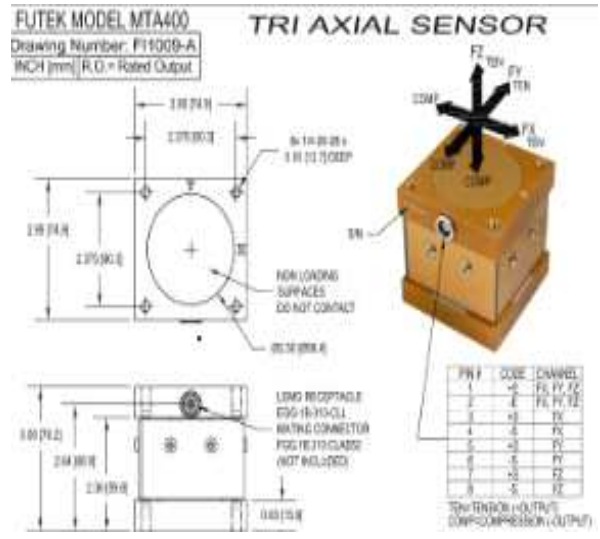

Figure $3 b$. Futek 3 axis load cell. 


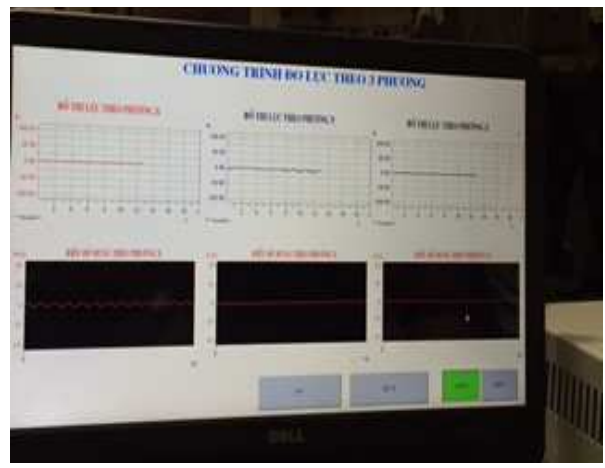

Figure 3c. Program shear 3D focre measurement.

Workpiece Material was SKD11 harden steel with hardness of 58-60 HRC. Workpiece has same size of $70 \times 30 \times 25 \mathrm{~mm}$. The properties of material are shown in Table 5 .

Table 5. Composition of chemical elements in SKD11 steel.

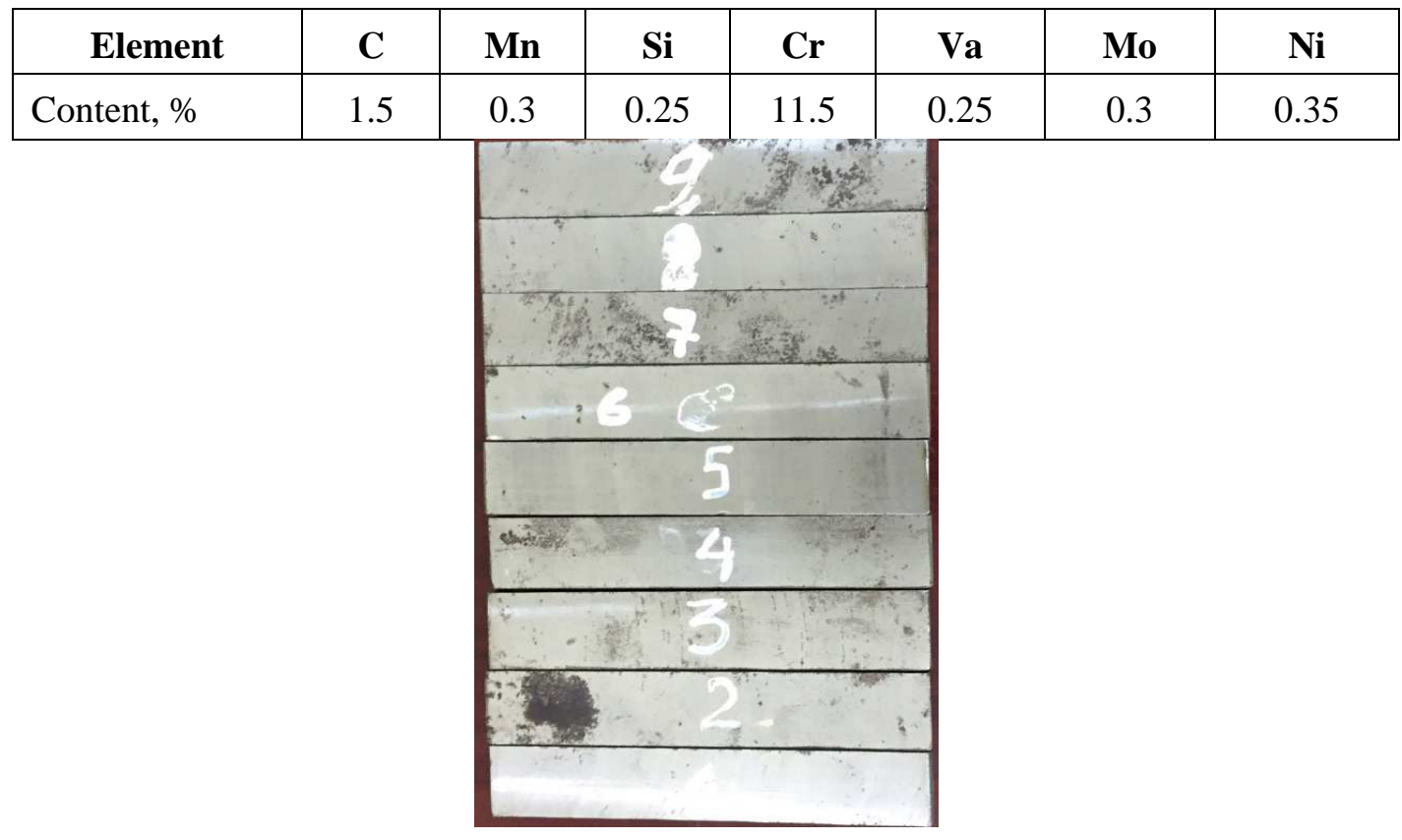

Figure 4. Screenshot of the workpiece used in the experiment.

\subsubsection{Experiment}

The experiment setup is shown in Fig. 5. 


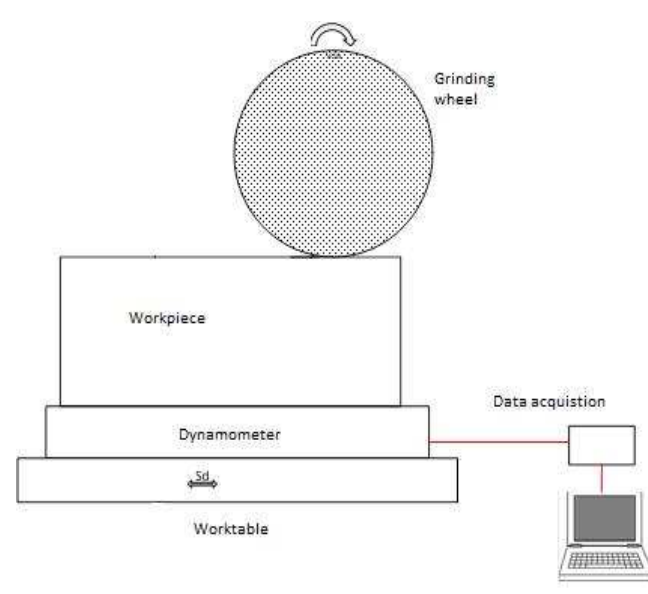

Figure 5a. Experiment set - up.

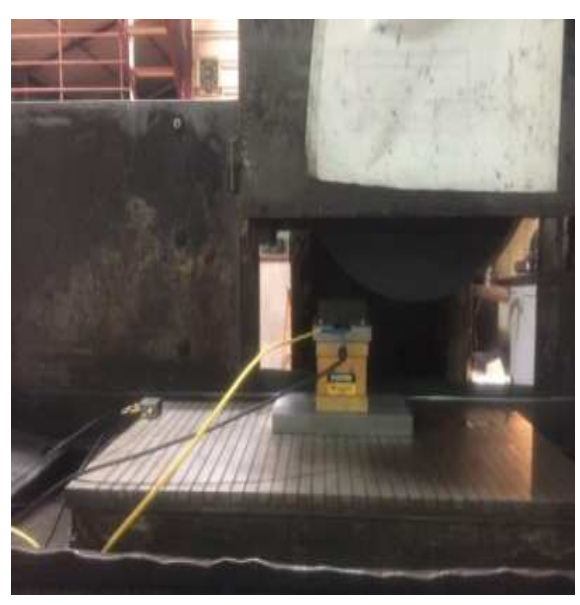

Figure $5 b$. Experiment when flat grinding.

The process parameters are selected depending on the equipment, cutting tools, machining materials (Table 6).

Table 6. Value parameters in experiment technology.

\begin{tabular}{|l|c|c|c|c|}
\hline \multirow{2}{*}{ Parameter } & \multirow{2}{*}{ Design parameters } & \multicolumn{3}{c|}{ Level } \\
\cline { 3 - 5 } & & Low & Medium & High \\
\hline Rate of feel s (m/min) & P1 & 12 & 15 & 20 \\
\hline Depth of cut t (mm) & P2 & 0.02 & 0.05 & 0.07 \\
\hline Segment grinding wheel & P3 & 0 & 20 & 24 \\
\hline
\end{tabular}

\subsection{Experiment sampling using Taguchi method}

\subsubsection{Orthogonal matrix according to Taguchi}

Experiment was set up as defined in Table 7.

Table 7. Orthogonal matrix according to Taguchi L9 of 3 parameters and 3 levels.

\begin{tabular}{|c|c|c|c|}
\hline Experiment No. & P1 $(\mathrm{m} / \mathrm{min})$ & P2 $(\mathrm{mm})$ & P3 (Segment) \\
\hline 1 & 12 & 0.02 & 0 \\
\hline 2 & 12 & 0.05 & 20 \\
\hline 3 & 12 & 0.07 & 20 \\
\hline 4 & 15 & 0.02 & 24 \\
\hline 5 & 15 & 0.05 & 0 \\
\hline 6 & 15 & 0.07 & 0 \\
\hline 7 & 20 & 0.02 & 20 \\
\hline 8 & 20 & 0.05 & 0.07 \\
\hline 9 & 20 & & \\
\hline
\end{tabular}




\subsubsection{Calculation results Taguchi experimental method}

Table 8. Value of signal to noise ratio $\eta=\mathrm{S} / \mathrm{N}$.

\begin{tabular}{|c|c|c|c|c|c|c|c|c|}
\hline Experiment & P1 & P2 & P3 & $P_{1}$ & $P_{2}$ & $P_{3}$ & $\bar{P}$ & $\eta_{i}$ \\
\hline 1 & 1 & 1 & 1 & 14.96 & 15.09 & 16.35 & 15.47 & -23.79 \\
\hline 2 & 1 & 2 & 2 & 19.26 & 18,15 & 17.25 & 18.22 & -25.22 \\
\hline 3 & 1 & 3 & 3 & 21.28 & 20.74 & 22.34 & 21.45 & -26.63 \\
\hline 4 & 2 & 1 & 2 & 10,09 & 9,2 & 8,98 & 9.42 & -19.49 \\
\hline 5 & 2 & 2 & 3 & 18.45 & 17.62 & 17.25 & 17.77 & -24.99 \\
\hline 6 & 2 & 3 & 1 & 22.14 & 21.59 & 21.06 & 21.60 & -26.69 \\
\hline 7 & 3 & 1 & 3 & 14.59 & 13.67 & 15.34 & 14.53 & -23.26 \\
\hline 8 & 3 & 2 & 1 & 19.86 & 18.62 & 17.98 & 18.82 & -25.5 \\
\hline 9 & 3 & 3 & 2 & 21.04 & 20.62 & 19.27 & 20.31 & -26.16 \\
\hline
\end{tabular}

From the above experiment we can calculate and have results in Table 9.

Table 9. ANOVA analysis of factors table for cutting power $\mathrm{P}(\mathrm{N})$.

\begin{tabular}{|c|c|c|c|c|}
\hline Variation & F & SS & MS & C (\%) \\
\hline P1 & 2 & 68.04 & 34.02 & 23.04 \\
\hline P2 & 2 & 16.10 & 8.05 & 5.45 \\
\hline P3 & 2 & 62.28 & 31.14 & 21.09 \\
\hline P1 $\times$ P2 & 4 & 21.18 & 5.29 & 7.17 \\
\hline P1 $\times$ P3 & 4 & 60.64 & 15.16 & 20.53 \\
\hline P2 $\times$ P3 & 4 & 20.68 & 5.17 & 7 \\
\hline P1 $\times$ P2 $\times$ P3 & 8 & 46.35 & 43.23 & 15.72 \\
\hline Sum & 80 & 295.27 & - & 100 \\
\hline
\end{tabular}

\subsection{ANOVA analysis}

From the experimental results we calculated the variance and obtained the results as shown in Table 9.

\subsection{Results and Discussions}

According to the results of signal to noise ratio $\eta$ as shown in Table 8, we can see that in the 4th experiment the performance value of ratio $\eta$ by the interference signal $(\mathrm{S} / \mathrm{N})$ is the smallest then the impact of process parameters to cutting force is minimal. 
From the mean value of process parameters (feed rate, cutting depth and the number of segments) P1, P2, P3, we can see the cutting force P (obtained from the three components) and performance " $\eta$ " in Table 8. The Figures 6 a, b and c show the influence of the average value of signal to noise ratio $(\mathrm{S} / \mathrm{N}$ ) under different feed rate, cutting depth and the number of segments in machining SKD11steel.

From the graphs in Figs. 6a, 6b, $6 \mathrm{c}$ we can notice that the biggest impact on cutting force is at level 1 when changing cutting depth, level 2 when changing feed rate and level 2 when changing the number of segments. At these levels the value of cutting force is minimal and most stable.

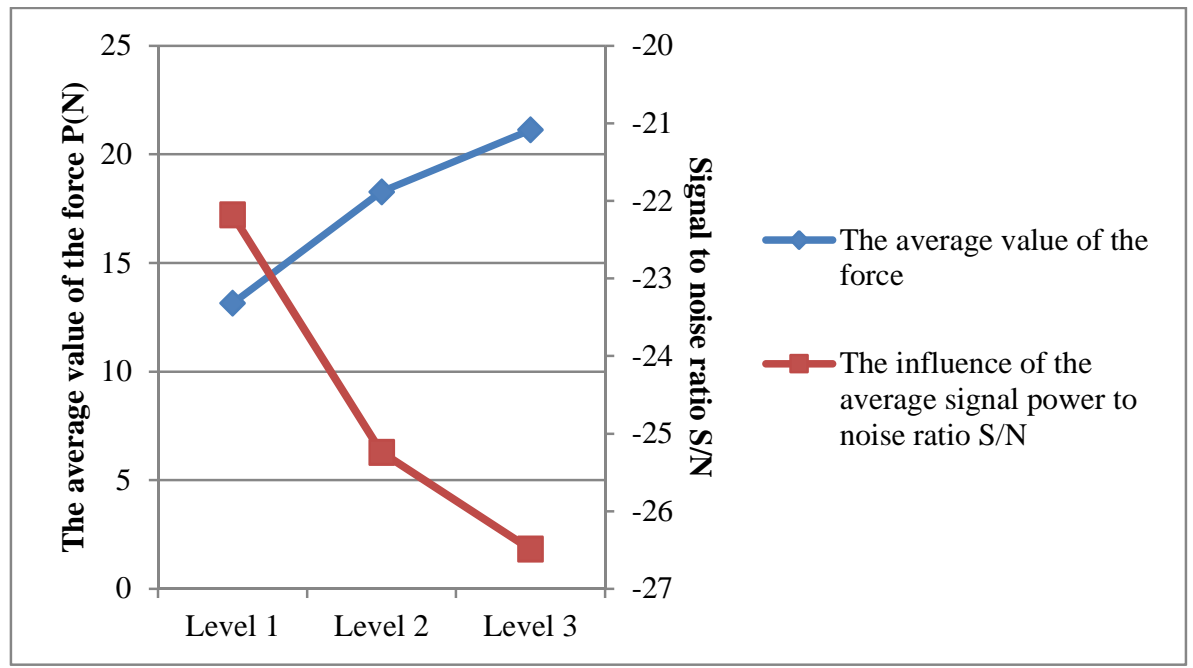

Figure $6 a$. The effect of signal to noise ratio to cutting force when changing the cutting depth by SKD11 steel using inclined segmented grinding wheel.

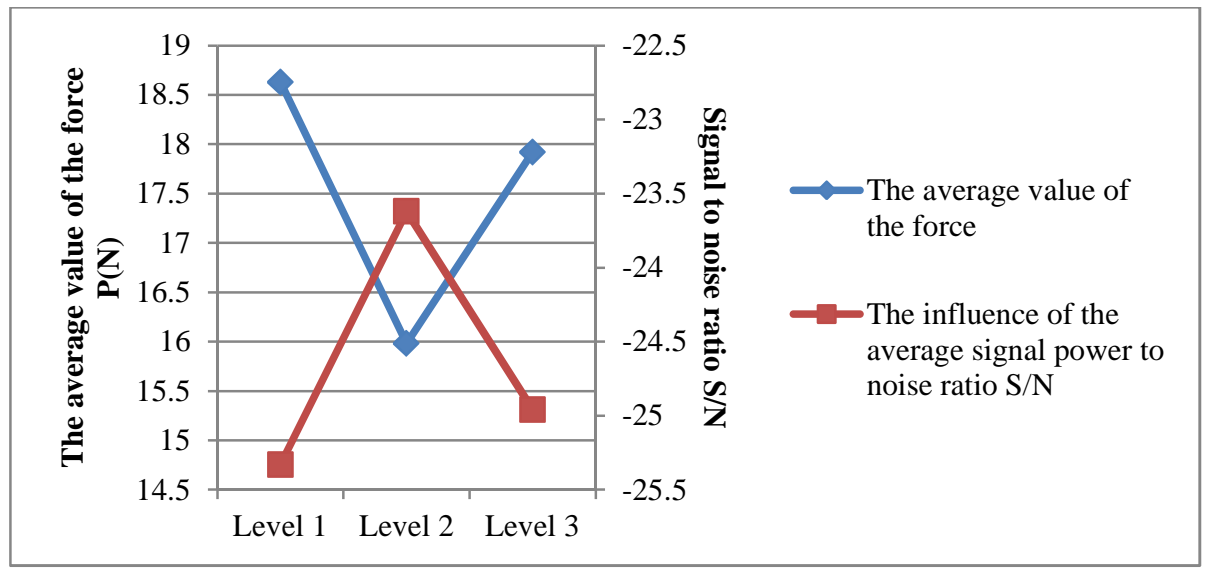

Figure $6 b$. The effect of signal to noise ratio to cutting force when changing feed rate by $\mathrm{S}$ KD11 steel using inclined segmented grinding wheel. 


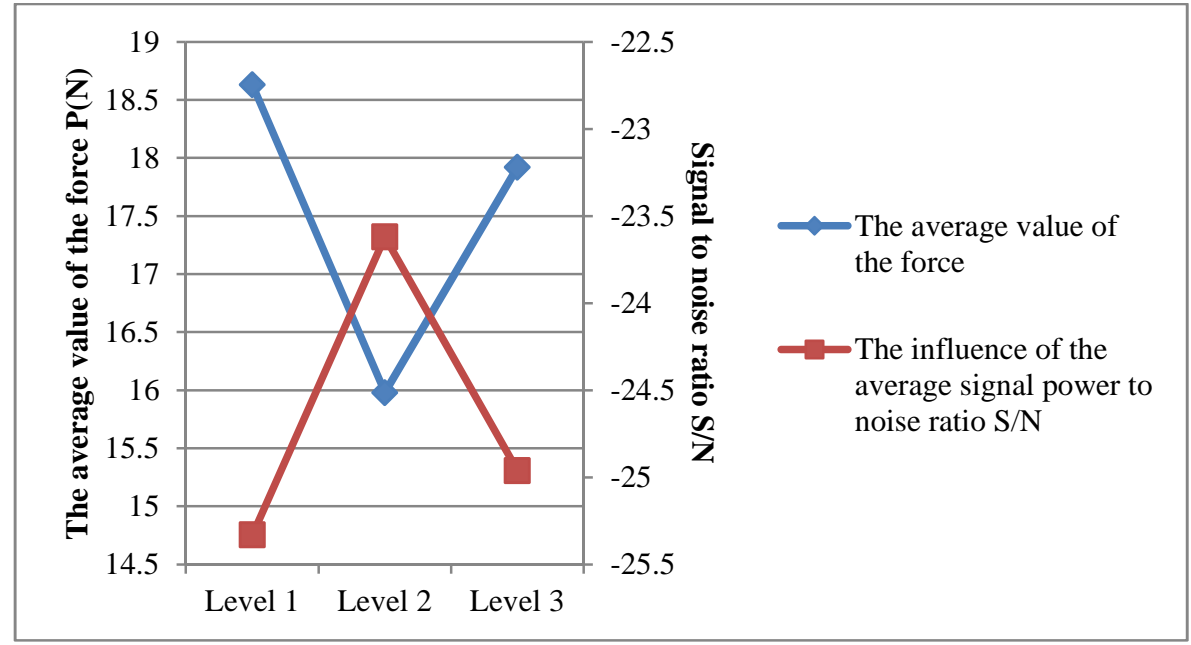

Figure 6c. The effect of signal to noise ratio to cutting force when changing the number of segments by SKD11 steel using inclined segmented grinding wheel.

\section{Discussion}

By calculating the signal to noise ratio, from Table 8 it shows that the 4th experiment with process parameters including the number of segments $Z=20$; depth of cut $t=0.02(\mathrm{~mm})$ and of feed rate $\mathrm{s}=15(\mathrm{~m} / \mathrm{min})$ gave the biggest value, i.e. $\eta=-19.49$, meaning that the impact of this experiment to cutting force is most stable.

Table 9 shows that, in the order feed rate of $23.04 \%$, the number of segment of $21.09 \%$ affects most to cutting force.

Compared to conventional grinding wheel, inclined segmented grinding wheel has more stable and smaller cutting force in surface grinding. It can be explained that when using conventional grinding wheel, the cutting process occurs continuously in the grinding surface, chips will move reversely with the wheel's velocity direction. These chips tend to gather in a group with increasing size and take the space in the porosity of grinding wheel. Then there will be no cutting edge in this zone. If chips can not move out of the cutting zone (the self sharpen ability of grinding wheel), grinding wheel will become dull and lose its cutting ability. Then cutting edges will be only slide process without cutting. It causes the increase in the tangential cutting force of grinding process along with the increase of friction and thermal. It is a disadvantage of conventional grinding wheel. With segmented grinding wheel because of the space created by the slot, chip is easier to move out from the cutting zone, then there will be no "dull" or "stick" in grinding process, therefore, the cutting ability will increase and also decrease cutting force.

\section{CONCLUSION}

The article refers to the study of the influence of some process parameters including the number of segment, depth of cut and feed rate to the cutting force when grinding the SKD11 steel by Taguchi methods and analysis of variance (ANOVA).

High accuracy and reliability (95\%) of the results of research using the Taguchi method and analysis of variance with three parameters, three levels of impact, three trials and three 
iterations of set points design, show the scientifically quantifiable impact of process parameter to cutting force when machining SKD11 steel on KENT flat grinding machine.

For minimizing shear forces within the selected parameters of technology systems, the local optimal values are shown as follows: number of segments to be $\mathrm{Z}=20$ (groove); depth of cut to be $\mathrm{t}=0.02(\mathrm{~mm})$; and feed rate to be $\mathrm{s}=15(\mathrm{~m} / \mathrm{min})$.

\section{REFERENCES}

1. Banh Tien Long, Tran Sy Tuy, Tran The Luc - Principles of material processing, Science and Technology Publishing House, Ha Noi, 2013 (in Vietnamese).

2. Pham Dinh Tan - Curriculum principles cutting and cutting tools, Education Publishing House, 2005 (in Vietnamese).

3. Julie Z. Zhang, Joseph C. Chen, E. Daniel Kirby - Surface roughness optimization in an end-milling operation using the Taguchi design method, Journal of Materials Processing Technology 184 (2007) 233-239.

4. Taranveer Singh, Khushdeep Goyal, Parlad Kumar - To Study the Effect of Process Parameters for Minimum Surface Roughness of Cylindrical Grinded AISI 1045 Steel, Manufacturing Science and Technology 2 (2014) 56-61.

5. Nguyen Thi Phuong Giang, Banh Tien Long, Tran The Luc - The influence of the cutting parametres in cylindrical grinding using highspeed grinding wheel produced by Hai Duong grinding wheel factory, Journal of Science \& Technology - Hanoi University of Industry, ISSN 1859-3585 57 (2006) 28-31 (in Vietnamese).

6. Nguyen Tien Dong, Nguyen Thi Phuong Giang - Reducing gringding forces in machining Ceramics using segmented grinding wheel, Journal of Science \& Technology - Technical universities, ISSN 0868-3980 81 (2011) 86-90 (in Vietnamese).

7. Nguyen Trong Hung, Phung Xuan Son - Design of experiments in mechanical engineering, Construction Publishing House, Ha Noi, 2016 (in Vietnamese).

8. NTU, Cutting Mode Search, Faculty of Mechanical Engineering, Nha Trang University (in Vietnamese).

9. Nguyen Trong Hung, Nguyen Anh Tu, Ngo Van Chuyen - Research the minimization of surface roughness using the Taguchi method in CNC turning mounting shaft process. Journal of Science \& Technology - Hanoi University of Industry, ISSN 1859-3585 36 (2016) 37-40 (in Vietnamese). 